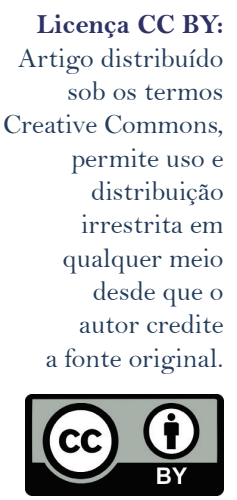

Licença CC BY: Artigo distribuído permite uso e distribuição alquer meio desde que $o$ autor credite a fonte original. BY

\author{
TURISMO DE INTERCÂMBIO: AS CONTRIBUIÇÕES \\ DA EXPERIÊNCIA AFEBRAE/SCHLOSS HOTEL LISL \\ GMBH \& CO.KG. NA ALEMANHA
}

\author{
FOREIGN EXCHANGE TOURISM: THE CONTRIBUTIONS \\ OF THE AFEBRAE/SCHLOSS HOTEL LISL \\ GMBH \& CO.KG. EXPERIENCE, IN GERMANY
}

ANDRÉlA CAROLINE SCHNEIDER'
Universidade Feevale, Novo Hamburgo, Rio Grande do Sul, Brasil

MARY SANDRA GUERRA ASHTON ${ }^{2}$

Universidade Feevale, Novo Hamburgo, Rio Grande do Sul, Brasil

DATA DE SUBMISSÃO: 27/06/2018 - DATA DE ACEITE: 18/03/2019

\begin{abstract}
RESUMO: Esse estudo tem o objetivo de investigar as contribuições da experiência do intercâmbio em Hotelaria e Gastronomia promovido entre a AFEBRAE e Schloss Hotel Lisl GmbH \& Co. KG, na Alemanha, para os participantes do intercâmbio entre os anos 2010 e 2012. Para tanto, adotou autores consagrados nessa temática de estudos e utilizou o método exploratório-descritivo e interpretativo com exemplo de caso numa abordagem qualitativa, tendo como procedimentos técnicos a pesquisa bibliográfica e de campo em estudo específico do referido programa de intercâmbio. Entre os resultados obtidos, constatou-se que as principais contribuições da realização deste intercâmbio, estão ligadas à qualificação profissional, amadurecimento pessoal e ampliação dos conhecimentos em âmbito cultural, social, disciplinar.
\end{abstract}

PALAVRAS-CHAVE: Turismo. Intercâmbio. Contribuições do intercâmbio AFEBRAE. Alemanha.

ABSTRACKT: Diese Studie zielt darauf ab, die Beiträge der Erfahrungsaustausch im Hotellerie und Gastronomie für die Teilnehmer gefördert zwischen AFEBRAE und Schloss Hotel Lisl GmbH \& Co. KG in Deutschland, für Austauschteilnehmer zwischen 2010 und 2012. Zu untersuchen. Daher nahm die Arbeit Autoren in dieser thematischen Studien geweiht und nutzt die deskriptive und interpretative Sondierungsverfahren mit Musterkoffer einen qualitativen Ansatz, mit den technischen Verfahren bibliographische und Feldforschung in bestimmten Studie des Austauschprogramms .Zu den Ergebnissen wurde festgestellt, dass die wichtigsten Beiträge zum Abschluss dieses Austauschs an die berufliche Qualifikation, persönliches Wachstum und Erweiterung des Wissens, in Kulturellen, Sozialen und Disziplinären Rahmen verbunde sind.

1 Acadêmica do Curso de Letras, Ivoti, RS, Brasil. E-mail: schneider.andreia@hotmail.com. Orcid: https://orcid. org/0000-0001-9947-2128

2 Pesquisadora e Professora Titular na Universidade Feevale, Novo Hamburgo, Rio Grande do Sul, Brasil. Doutora e Mestre em Comunicação Social pela PUCRS, Especialista em Gestão do Turismo e Bacharel em Turismo pela PUCRS. E-mail: marysga@feevale.br. Orcid: http://orcid.org/0000-0003-4467-9417 
STICHWORTE: Tourismus. Austauschprogramm. Beiträge aus dem AFEBRAE-Austauschprogramm. Deutschland.

\begin{abstract}
This study investigates the contributions of foreign exchange tourism in Hotel Management and Gastronomy, promoted between the AFEBRAE and the Schloss Hotel Lisl GmbH \& Co. KG, in Germany, for foreign exchange participants in the period 2010 to 2012. For this, it adopts renowned authors on the them, and uses the exploratory-descriptive and interpretative methods as an example of a case, using a qualitative approach. In terms of technical procedures, it uses bibliographic research and a specific field study on the foreign exchange program in question. Among the results, it was observed that the main contributions of taking part in this foreign exchange are related to professional qualification, personal growth, and increasing knowledge in the cultural, social and disciplinary areas.
\end{abstract}

KEYWORDS: Tourism. Foreign Exchange. Contributions of the AFEBRAE foreign exchange. Germany.

RESUMEN: Este estudio tiene el objetivo de investigar las contribuciones de la experiencia del intercambio en Hotelería y Gastronomía promovido entre la AFEBRAE y la Schloss Hotel Lisl GmbH \& Co. KG, en Alemania, para los participantes del intercambio entre los años 2010 y 2012. Para tanto, adoptó autores consagrados en esta temática de estudios y utilizó el método exploratorio descriptivo e interpretativo con ejemplo de caso en un abordaje cualitativo, teniendo como procedimientos técnicos la investigación bibliográfica y de campo en estudio específico del referido programa de intercambio. Entre los resultados obtenidos, se constató que las principales contribuciones de la realización de este intercambio están relacionadas a la calificación profesional, a la maduración personal y a la ampliación de los conocimientos en ámbito cultural, social, disciplinar.

PALABRAS-CLAVE: Turismo. Intercambio. Contribuciones del intercambio AFEBRAE. Alemania.

\title{
INTRODUÇÃO
}

Considerado entre os setores que mais cresce, se desenvolve e movimenta a economia no mundo, o turismo tem consolidado sua importância e já, em muitos países, é a principal fonte de renda para a população local. Com a atual diversidade da oferta turística e a expansão do mercado em nível mundial, o Turismo de Intercâmbio é um segmento de relevante contribuição para a formação pessoal e profissional das pessoas que escolhem ter a experiência de uma viagem motivada pelas práticas vinculadas à proposta de intercâmbio em um país estrangeiro.

Vale ressaltar que a internacionalização está entre as principais pautas do ensino superior de turismo, pois impacta diretamente na vida profissional dos intercambistas e, assim, na relação com o desenvolvimento do setor.

Segundo a Organização Mundial do Turismo (2003), os intercâmbios proporcionam aos intercambistas a possibilidade de imersão na cultura local, pois passam a conhecer o modo de vida, o idioma, os hábitos e os costumes do lugar, além de desenvolver novas habilidades profissionais dentro de um padrão internacional que envolve disciplina, formalidade, respeito e padrão de qualidade na prestação de serviços e, ainda, a conquista de experiências e conhecimentos que contribuem para a especialização em nível internacional.

Percebendo o quanto os programas de intercâmbios estão sendo reconhecidos como fatores de desenvolvimento pessoal e profissional, muitas instituições de ensino 
superior, redes hoteleiras e empresas privadas estão estabelecendo parcerias, promovendo e incentivando estas relações de troca socioculturais.

Assim, justificam-se o interesse e a importância em estudar esse intercâmbio realizado em um complexo turístico na Alemanha, do qual a autora principal participou, visto que este proporciona vivências e experiências de aprendizado pessoal nas referidas áreas, sendo de considerável contribuição para o meio acadêmico e social. Esse intercâmbio é organizado pela AFEBRAE, agência sediada em Nova Petrópolis, Rio Grande do Sul, Brasil, e acontece na cidade de Hohenschwangau no sul da Alemanha, com duração de um ano, com o intuito de capacitar para atuar na área de hotelaria e gastronomia, além da prática diária do idioma alemão.

Esse estudo teve o objetivo de investigar as contribuições da experiência do intercâmbio em Hotelaria e Gastronomia promovido entre a AFEBRAE e Schloss Hotel Lisl GmbH \& Co. KG para os participantes das três edições (2010; 2011 e 2012). Busca descrever esse processo de intercâmbio, apresentando a parceria entre AFEBRAE e Schloss Hotel Lisl $\mathrm{GmbH} \&$ Co. $K G$, além de caracterizar a região e o complexo turístico na Alemanha, local onde é realizado esse intercâmbio, bem como investigar junto aos participantes do intercâmbio das edições de 2010, 2011 e 2012 as contribuições percebidas com esta experiência. Vale destacar que a autora principal participou da edição 2010 do intercâmbio.

\section{MARCO TEÓRICO}

\section{TURISMO DE INTERCÂMBIO}

O turismo de intercâmbio é um segmento do turismo que vem crescendo e se desenvolvendo, principalmente entre os jovens e os estudantes. Esta prática é classificada por Bartell (apud MOROSINI, 2003) como trocas internacionais que estão relacionadas à educação, ao conhecimento e ao aprendizado vinculado à internacionalização. Conforme o Ministério do Turismo (2008, p. 15), o turismo de intercâmbio constitui-se em uma movimentação turística gerada por "atividades e programas de aprendizagem e vivências para fins de qualificação, ampliação de conhecimento e de desenvolvimento pessoal e profissional". Para Vasconcelos (2014), o turismo de intercâmbio visa movimentar turistas or meio de atividades e programas de aprendizagem. A partir desses intercâmbios estudantis, há promoção do destino, uma vez que os próprios estudantes divulgam o local em seu país de origem.

Os intercâmbios são universalmente conhecidos, e é por meio deles que fatores de caráter profissional e pessoal são agregados ao currículo do indivíduo, além de influenciar positivamente na vida dos intercambistas. A realização de um intercâmbio, para muitos, pode ser a chance de uma mudança interior e pessoal na sua visão de realidade, pois, conforme Mota (2009), o turismo de intercâmbio é muito amplo e oferta vários tipos de cursos e atividades com intuitos distintos, podendo assim atender a diferentes demandas. Com as diversas modalidades de intercâmbio, o participante desenvolve competências que contribuem para ascensão em sua carreira (TOMAZZONI E OLIVEIRA, 2013, p. 389). 
Segundo Vasconcelos (2014, p. 27), o turismo de intercâmbio é um novo segmento que se expande no mercado turístico e que comprova que "o turismo não se resume em apenas lazer e fruição", pois por meio do intercâmbio o turista "realiza uma comunicação intercultural, estuda e desfruta dos atrativos naturais e histórico-culturais no destino." Assim, também está relacionado à ampliação das relações sociais e geração de aprendizagem e conhecimento (TAMIÃO, 2010).

Conforme Menezes (2004, p. 20), "pela cultura estrangeira se pode intentar e compreender os significados da vida de outros grupos sociais, visitar lugares que não são os seus para compreender sua história e cultura". Tavares (2008, p. 238) acrescenta "a busca de conhecimento aprofundado de uma cultura, de uma língua ou da área de atuação profissional" entre os principais motivadores à realização de um intercâmbio. O foco da viagem de intercâmbio é o objetivo da experiência vivida no local/país distinto do seu habitual e não o destino turístico em si.

Assim, o intercâmbio constitui-se de experiência turística cultural profissional, pessoal e educacional (MOTA, 2009; BENI, 2011; NOVELINO, 2016). Teles (2004) considera que, além de fluência na língua estrangeira, o intercâmbio é laboratório para testar e desenvolver habilidades profissionais e a capacidade de enfrentar problemas por conta própria em um ambiente desconhecido. Ao decidir participar de um intercâmbio, o jovem está rompendo fronteiras, barreiras culturais e está procurando ir ao encontro de algo novo, dispondo-se a aprender e absorver novos conhecimentos, provocando um despertar de uma amplitude de sentimentos e de novos questionamentos (SEBBEN, 2007).

A utilização do tempo livre não obedece a modelos preestabelecidos para todos nem está necessariamente separada da atividade profissional ou cultural. [...]. O tempo livre pode ser utilizado para reforçar habilidades ou conhecimentos necessários à atividade profissional. Essa área é cada vez mais explorada, ampliando a possibilidade de "turismos" ligados a atividades de aperfeiçoamento e atualização profissional. (TRIGO, 1998, p. 34, grifo do autor).

A realização de um intercâmbio pode gerar melhorias na adaptação a novos lugares e ao desenvolvimento de novas habilidades, credenciando o indivíduo a encarar desafios pessoais e corporativos. Para Panosso Neto e Ansarah (2009), são convenientes viagens que visem a um aprendizado mais profundo, por meio da diversidade de experiências no campo profissional e visão multicultural. Ao vivenciar outra cultura, os aspectos cognitivos e emocionais são aprimorados por meio dessa experiência, contribuindo para a formação tanto profissional quanto pessoal. A pessoa que participa de um intercâmbio se envolve na aprendizagem e na interação dentro de um ambiente multicultural, partilhando semelhanças e diferenças. Essa qualificação deve ser entendida como a elevação do grau de aptidão ou domínio em uma atividade ou habilidade, a experiência vivenciada promoverá e facilitará sua vida profissional.

Conforme Mac-Dowell (1998), Tamião (2010), Pereira (2005), Tavares (2008), Fleuri apud Lopez (2000), Sebben (2007), Mota (2009), Tomazzoni e Oliveira (2013), o enriquecimento pessoal, a ampliação dos conhecimentos, a troca de experiências, as vivências culturais, o 
aprendizado, o amadurecimento, a autonomia, o aumento de autoestima e o autoconhecimento, o desenvolvimento de habilidades e de capacidades profissionais distintas, a liberdade, o aprimoramento e a possibilidade de fluência no idioma estrangeiro, além da descoberta de diferentes países e pessoas distintas, são abordados como algumas das contribuições mais marcantes para quem realiza este tipo de atividade.

Percebendo o quanto os programas de intercâmbios estão sendo reconhecidos como fatores de amadurecimento, autonomia, desenvolvimento pessoal e profissional, os autores de referência deste estudo afirmam que no esforço sadio de romper fronteiras, limitações, preconceitos, inseguranças e barreiras culturais, nasce um novo indivíduo. Além disso, a partir das mudanças impostas pelas novas tecnologias e comunicações, observase também a mudança nos modos e nos estilos de vida das pessoas, promovendo maior investimento pessoal na busca pelo conhecimento. Mac-Dowell (1998) afirma que, em função do crescimento econômico, as mudanças são uma proposta de desafio estimulante e as pessoas procuram, além das fronteiras, formas distintas de aprendizados para ampliar seus conhecimentos, buscando uma educação qualificada, concordando assim que o valor prático de uma educação no exterior é amplamente reconhecido quando do seu retorno ao país de origem.

Para "aprender sobre uma nação e conhecer seu povo é necessário viver nesse outro país por um período de tempo, encontrar pessoas e conversar com elas" (MAC-DOWELL, 1998, p. 12). A experiência internacional é a oportunidade de melhorar ou desenvolver habilidades e capacidades profissionais distintas, que são muito importantes tanto para o crescimento pessoal como profissional. Esteves, Galdini e Magliocca (2011, p. 141) expressam a questão da disciplina, que deve acompanhar a decisão de participar de programa de intercâmbio em outros países, pois "tem um papel central na construção da carreira". Num processo seletivo profissional, a diferença não está em ter feito ou não um intercâmbio, mas sim em como a pessoas se envolvem e se dedicam a cada uma dessas oportunidades e "o significado atribuído, bem como os aprendizados adquiridos durante essas experiências." (ESTEVES, GALDINI, MAGLIOCCA, 2011, p. 51).

Cada dia mais as empresas nacionais e internacionais, assim como órgãos públicos do país, requerem no seu quadro funcional jovens com experiência no exterior por entenderem que essas pessoas têm perfil arrojado, iniciativa, flexibilidade e criatividade. (SEBBEN, 2001, p. 6).

Para Tamião (2010, p. 5), a razão do intercâmbio estudantil é a vontade de aprimorar seus conhecimentos e sua atividade profissional, além de conhecer novas culturas e pessoas. "O intercâmbio oferece diferenciação nos estudos, enriquece o currículo escolar, contribuindo para ingresso no mercado de trabalho".

Mac-Dowell (1998, p. 12) acrescenta que "experimentar outra cultura enriquece o indivíduo de conhecimentos, além de ajudá-lo a compreender melhor o mundo e apreciar mais a sua própria cultura". Em relação à vida profissional, para os que tiveram uma experiência internacional no mercado competitivo da atualidade, este será um fator determinante na disputa de um trabalho, considerando principalmente que:

Os empregadores reconhecem a ligação entre uma experiência no exterior e a construção de parcerias de sucesso com empresas multinacionais. Aprender um 
idioma é extremamente importante. Aliar isso à cultura e aos contatos pessoais feitos durante um curso agrega inúmeros valores e esses novos valores educacionais são requisitos necessários não apenas para o indivíduo se incorporar ao mundo do trabalho, mas também, para o exercício da cidadania. (MAC-DOWELL, 1998, p. 12).

O intercâmbio é uma excelente maneira de adquirir fluência em outro idioma e estar exposto a situações de amadurecimento pessoal. Assim, "a experiência passou a ser vista como uma evidência de flexibilidade e adaptabilidade da pessoa a diferentes culturas." (ESTEVES, GALDINI, MAGLIOCCA, 2011, p. 51). Somados à vantagem competitiva profissional de quem domina mais de uma língua, e aqueles que puderam ter uma vivência internacional consistente (PEREIRA, 2005, p. 49).

Os contatos pessoais proporcionam, segundo Rabany (2003), interação cultural e sociológica, não sendo reduzida a apenas uma simples relação de conhecimento, a educação intercultural trata da interação do sujeito, "isto significa uma relação de troca e reciprocidade entre pessoas [...]" (FLEURI apud LOPEZ, 2000, p. 35).

Pode-se destacar que entre os principais benefícios que uma pessoa obtém ao efetuar um programa de intercâmbio estão: o desenvolvimento pessoal (amadurecimento, liberdade, autonomia, aumento de autoestima e autoconhecimento), reconhecimento de diferenças culturais e desenvolvimento de perspectiva global mais ampla. (TAVARES, 2008, p. 238).

Na procura por enriquecer o caráter de seus participantes, agregando mais valor e uma diferenciação no currículo, o intercâmbio pode contribuir para a carreira profissional e, acima de tudo, crescimento pessoal, sendo necessário que este praticante seja muito mais independente, autoconfiante e livre para tomar suas decisões.

Considerando estes e demais pontos que são abordados, é plausível e positivo para as pessoas que realizam um intercâmbio afirmar que "o saldo é sempre positivo e a maioria aprende a ter uma visão mais ampla da vida, voltam amadurecidos [...]." (MAC-DOWELL, 1998, p. 6).

Logo, o turismo de intercâmbio é ferramenta de poder educacional, capaz de acrescentar aspectos enriquecedores para a formação pessoal e profissional de um indivíduo, por meio do provável contato com outras realidades, culturas e situações, em que irá aprender e vivenciar diferentes situações que o farão amadurecer para um futuro profissional de sucesso (SEBBEN, 2007).

\section{METODOLOGIA}

Para o desenvolvimento desse estudo, foi utilizado o método exploratóriodescritivo com abordagem qualitativa, com base em Gil (2009), Dencker (2002), Prodanov e Freitas (2013), Denzin e Lincoln (2006). Quanto às técnicas de pesquisa, foi inicialmente realizada revisão bibliográfica e pesquisa de campo.

A revisão da literatura foi útil para a sustentação e base teórica, contribuindo para a compreensão da temática do turismo de intercâmbios conforme desenvolvido 
por autores, como: Sebben (2007), Mac-Dowell (1998), Tamião (2010), Pereira (2005), Tavares (2008), Fleuri apud Lopez (2000), Vasconcelos (2014), Mota (2009), Tomazzoni e Oliveira (2013), Beni (2011), Novelino (2016), entre outros.

A pesquisa de campo para a coleta dos dados consistiu na aplicação do instrumento questionário aos participantes do intercâmbio em Hotelaria e Gastronomia, promovido entre a AFEBRAE e Schloss Hotel Lisl GmbH \& Co. KG das edições de 2010, 2011 e 2012. E teve o objetivo de investigar as contribuições em âmbito pessoal e profissional da realização do intercâmbio em questão. As questões propostas buscaram identificar o perfil dos participantes e suas opiniões sobre a realização desse intercâmbio. Para tanto, foi utilizado um roteiro semiestruturado contendo uma questão aberta e três questões fechadas de escolha simples e classificações de acordo com o grau de importância e satisfação. A aplicação foi realizada em sua totalidade via correio eletrônico (e-mail) entre os dias 19 de abril e 04 de maio de 2014. A amostra foi não probabilística e foi composta adotando como critérios de inclusão ter realizado o intercâmbio da AFEBRAE e Schloss Hotel Lisl GmbH \& Co.Kg. entre 2010-2013 e se disponibilizar a responder as questões. Obteve-se a participação de 16 intercambistas que realizaram o intercâmbio em estudo e atingindo o total de intercambistas do período investigado das edições de 2010, 2011 e 2012.

Vale ressaltar que a autora principal realizou o referido intercâmbio na edição 2010 e que todas as figuras (fotografias) que integram o texto são de sua autoria e fazem parte do seu arquivo pessoal. Os resultados apresentam o perfil dos intercambistas, contendo informações sobre gênero, idade, grau de escolaridade, ano da realização do intercâmbio e cidade ou estado de residência. Além das questões específicas que contêm informações sugerindo possíveis aprendizados durante a realização do intercâmbio, algumas contribuições e benefícios da realização do mesmo e também aspectos que podem ter sido aprendidos contribuindo para o desenvolvimento profissional e pessoal de cada participante.

Foi adotado como exemplo de caso (YIN, 2006; GIL, 2009) o intercâmbio promovido entre a AFEBRAE e Schloss Hotel Lisl GmbH \& Co. Kg., focando nas edições 2010, 2011 e 2012. Inicialmente se buscaram caracterizar e descrever esse intercâmbio. Além disso, foram predefinidas categorias de análise referentes às contribuições pessoais e profissionais resultantes da realização deste intercâmbio.

\section{CASE DE INTERCÂMBIO AFEBRAE/SCHLOSS HOTEL LISL GMBH \& CO. KG.}

A AFEBRAE é uma agência de intercâmbios que iniciou suas atividades em 1988, está sediada em Nova Petrópolis, no Rio Grande do Sul, e promove intercâmbios no exterior, principalmente na Alemanha, em áreas que abrangem agricultura, floricultura, pecuária, enologia, hotelaria, gastronomia e turismo. A parceria entre a AFEBRAE e Schloss Hotel Lisl GmbH \& Co.Kg. surgiu em 2009, quando membros da Rota Romântica da Alemanha visitaram a região sul do Brasil e acordaram sobre a parceria para o estágio em Hotelaria e Gastronomia na Alemanha. Para tanto, foram estabelecidos como pré-requisitos para participação neste intercâmbio: necessidade da fluência do idioma alemão ou inglês; ser maior de 18 anos; ser solteiro; comprovar atuação em alguma aérea do turismo; ter cursado (ou estar cursando) curso relacionado ao turismo, gastronomia ou hotelaria; não ter filhos e ter disponibilidade para permanência de um ano na Alemanha. 


\section{CARACTERIZAÇÃO DO LOCAL DO INTERCÂMBIO}

Localizada no extremo sul da Alemanha, no estado da Baviera, Hohenschwangau é considerada aldeia de Schwangau, distrito de Füssen. Schwangaui conta com aproximadamente 3.400 moradores, sendo que em Hohenschwangau moram apenas funcionários do complexo turístico. A pouco mais de quatro quilômetros da divisa com a Áustria, a pequena cidade está encravada entre montanhas e lagos, conforme Figura 1.

Figura 1: Complexo turístico de Hohenschwangau

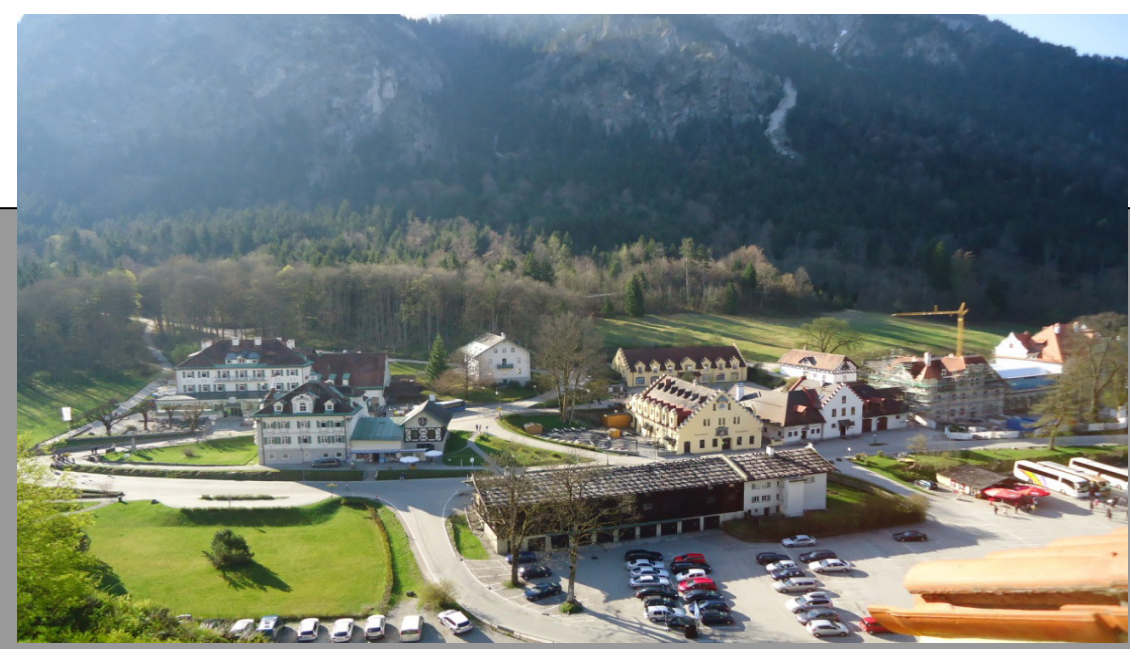

Fonte: Arquivo pessoal

"Considerado no país inteiro, uma economia modelo, o turismo é de grande significado e deve continuar a crescer. A Baviera é um sério destino turístico." (JOB; MAYER, 2013, p. 2, tradução nossa).

O turismo na Baviera oferece variedade e diversidade para fortalecer o país, que se tornou um destino atraente de opções para o ano inteiro. A lista de atrativos é longa, variando desde a geografia, aspectos regionais, cultura, história, costumes, impressionantes opções de esportes e outras atividades ao ar livre, especialidades culinárias, eventos, diversas opções de hotelaria e gastronomia, uma boa infraestrutura de transportes, um alto nível de segurança pública. (JOB; MAYER, 2013, p. 32, tradução nossa).

O desenvolvimento do Turismo na região aconteceu a partir de 1830, em função da introdução da indústria de laticínios, quando esta cultura agrícola e a paisagem verde funcionavam entre os principais fomentos ao turismo regional. A partir de $1850 \mathrm{o}$ alpinismo e outros esportes de inverno começaram a trazer mais público para esta região, os quais juntamente com a construção dos Castelos Hohenschwangau e Neuschwanstein, promoveram também o aumento do fluxo de turistas estrangeiros. Em 1934, o estado de Allgäu era destino de férias da KdF (Kraft durch Freude - Força através da Alegria) dos Nazistas. Em 1945, a região tornou-se atrativa para turistas franceses e americanos. E finalmente em 1972 o estado passou por uma reforma administrativa, com a qual ocorreu a divisão de cada região turística. 
A divisão de ofertas por regiões mostra a demanda do turismo principalmente em duas regiões - quando o turismo urbano é desconsiderado - Allgäu e Niederbayern, representam foco real. Somente aqui a atividade está relacionada à paisagem e bem-estar de visitantes em todas as épocas do ano, sendo assim fator decisivo da economia local. (JOB; MAYER, 2013, p. 2, tradução nossa).

Não existem confirmações sobre data e período de construção do Castelo Hohenschwangau (Figura 2), apenas o registro da reforma em 1832-1836 por Maximilian II para ser a casa de verão da Família Real. O filho de Maximilian II, Ludwig II cresceu com seu irmão Otto neste castelo e mandou construir o castelo Neuschwanstein (que significa Novo Cisne de Pedra), em 1869-1886. Ludwig II tinha fascinação por cisnes e, assim deu esse nome para sua maior construção (Neuschwanstein). A região dos castelos, como é conhecida nacionalmente a região de Allgäu, possui geografia singular, que somada ao encanto dos castelos e típicas casas dos povoados fazem parecer um conto de fadas. $\mathrm{O}$ vilarejo de Hohenschwangau, onde está localizado o complexo, recebe por ano mais de 1,5 milhão de turistas e em torno de 6 mil turistas por dia na alta temporada atraídos por:

Ar balsâmico em uma bela paisagem; as montanhas que elevam os olhos, e a graciosa planta (edelweis) que os leva para baixo; lagos cintilantes que na rocha refletem onde são elevadas. Flores, o cantar dos pássaros e ainda um Castelo encantado, com todo o romance da Idade Média, combinados com bom gosto e elegância contemporânea - o que mais se pode querer? (FRIEDRICH, 2013, p. 64, tradução nossa).

Nenhuma construção ou ponto turístico da Alemanha é tão visitado por turistas como os castelos Reais de Hohenschwangau (Figura 2) e Neuschwanstein (Figura 3). (KNAPP, 1999, p. 6, tradução nossa).

Figura 2: Castelo de Hohenschwangau

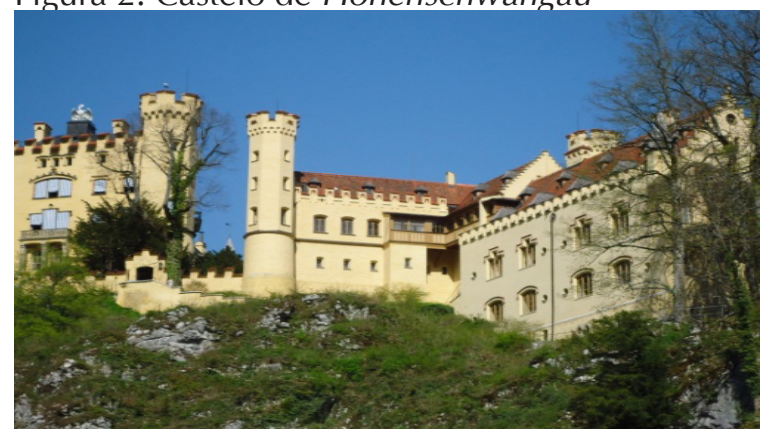

Fonte: Arquivo pessoal

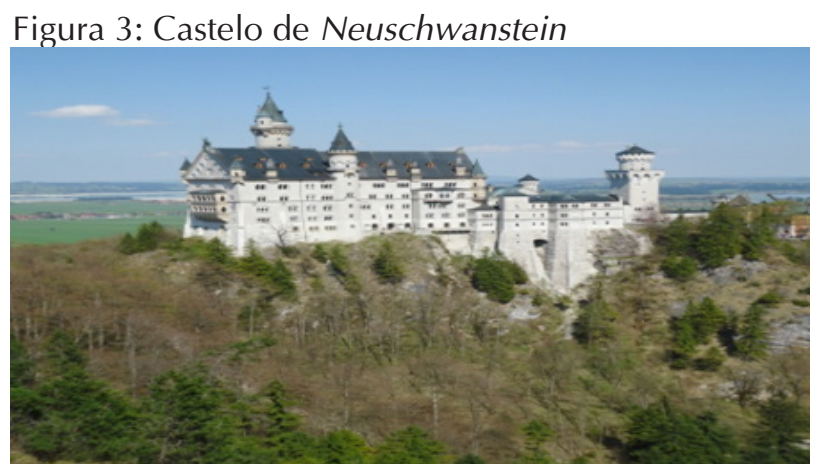

Fonte: Arquivo pessoal

Além dos castelos mencionados fazem parte deste complexo: o Museu dos Reis da Baviera, inaugurado em 2011; os 61 meios de hospedagem (hotéis, pousadas e pensões); os restaurantes; o lago Alpensee com pedalinhos; o Centro de Informações e Ingressos; e as lojas de souvenirs. Além de estacionamento, banheiros públicos, salão para festas e eventos, área privada para banho no lago Alpsee e ainda transporte de carroça e ônibus até os castelos. O vilarejo fica a aproximadamente $120 \mathrm{~km}$ de distância do Aeroporto Internacional de München (Munique), o mais próximo do complexo. Se for de carro pela A95 ou de trem, a viagem dura em média duas horas até Füssen para depois pegar o transporte local até o complexo de Hohenschwangau. 


\section{ATIVIDADES REALIZADAS PELOS INTERCAMBISTAS}

As atividades propostas no programa de intercâmbio em estudo são realizadas no complexo de Hohenschwangau, junto aos castelos de Hohenschwangau e Neuschwanstein, mais especificamente dentro dos Hotéis Lisl e Villa Jäger Haus e restaurantes Lisl e Schlossbräustüberl. Quando necessário, algumas atividades são exercidas no Hotel Schwangauer Hof, Garni Schloss Blick e Restaurante Alpenrose.

As atividades seguem os padrões de qualidade da região e priorizam o aprendizado, ampliação de conhecimentos técnicos e sobre a cultura regional e estão divididas em quatro setores principais, a saber: recepção, suítes, cozinha e restaurante, sendo que os intercambistas atuam por três meses em cada setor. Também recebem uniformes e crachás adequados a cada setor e tem início a familiarização do ambiente por meio de uma visita guiada para o reconhecimento de todo o complexo turístico (hotéis, restaurantes, castelos, bilheteria, museu e administrativo) e dos castelos (Hohenschwangau e Neuschwastein). Cada intercambista recebe uma agenda das suas funções e são explicadas as expectativas em relação ao desempenho dessas funções, sendo que a pontualidade e o padrão de qualidade são os pontos mais importantes.

Recepção - exige fluência do idioma alemão e inglês. Iniciativa, cordialidade, discrição e agilidade são características trabalhadas neste setor. As principais funções são: atendimento e auxílio ao público, hóspedes dos hotéis e grupos. Horário de trabalho das $09 \mathrm{~h}$ às $17 \mathrm{~h}$ ou $13 \mathrm{~h}$ às $21 \mathrm{~h}$. Os intercambistas da recepção, em parceria com os da cozinha do hotel, são responsáveis por traduzir o prato do dia para inglês, imprimir o cardápio e entregar aos coordenadores do restaurante para distribuição nas mesas do restaurante. Ligações solicitando reservas são encaminhadas diretamente para o setor responsável, tendo assim o sistema atualizado para todos. Grupos agendados para almoço, jantar ou pernoite são atendidos com exclusividade. O turno da noite encerra com o fechamento do caixa. As atividades no setor de reservas priorizam o interesse em aprender sobre solicitações de reservas para hospedagem individuais ou para grupos, comissão para agências, eventos, confirmações e cancelamentos.

Suítes - seguem o padrão de ambientação e identidade com a história local no estilo clássico. Horário de trabalho das $06 \mathrm{~h}$ às $14 \mathrm{~h}$ ou $14 \mathrm{~h}$ às $22 \mathrm{~h}$. O trabalho exige pouco conhecimento do idioma, porém requer discrição, respeito e atenção na realização das atividades diárias. Dentre as principais funções estão a limpeza e a organização das suítes e dos quartos dos hotéis com dedicação no atendimento aos hóspedes.

Cozinha - horário de trabalho das $10 \mathrm{~h}$ às $18 \mathrm{~h}$ ou $14 \mathrm{~h}$ às $22 \mathrm{~h}$. O desempenho dessa função requer conhecimento básico do idioma alemão. Exige disciplina quanto à conservação de alimentos, limpeza dos mesmos e higienização do ambiente. Proporciona também oportunidade de aprendizado de vocabulário em geral e técnicas profissionais específicas da cozinha internacional - gastronomia.

Restaurante - (Figura 4). Tem vista para ambos os castelos. São servidos os pratos mais requintados elaborados na cozinha do Hotel Lisl. Horário de trabalho: 06h às 14h, $11 \mathrm{~h}$ às $19 \mathrm{~h}$ ou $14 \mathrm{~h}$ às $22 \mathrm{~h}$. O trabalho neste setor exige conhecimento do idioma alemão e inglês, além da habilidade para lidar com pessoas das mais diversas culturas. As tarefas exigem um padrão de qualidade na prestação do serviço, respeito com os clientes, disciplina, descrição e flexibilidade. 
Figura 4: Restaurante Wittelsbach

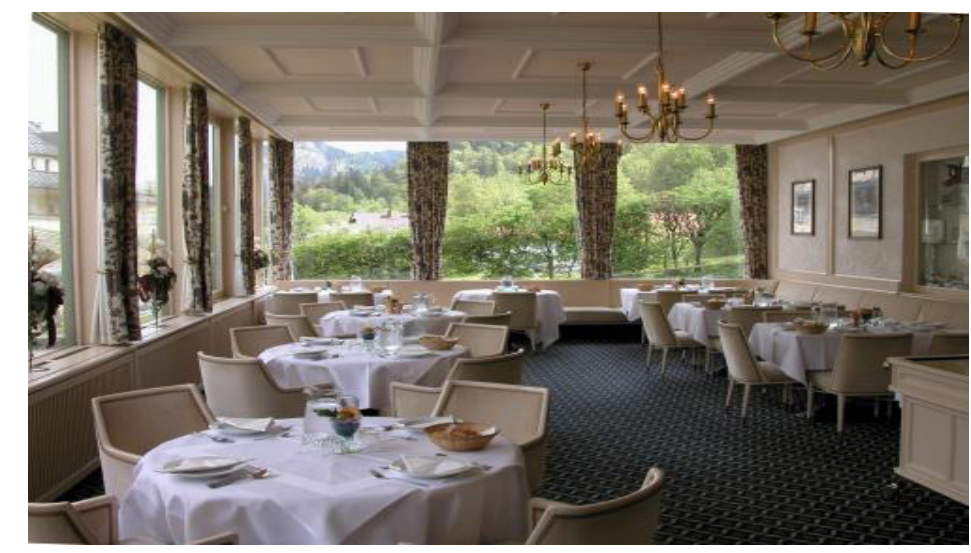

Fonte: Arquivo pessoal

Funções básicas desta atividade são ensinadas na prática, tais como: posição dos talheres sobre a mesa, posição do guardanapo, copos e demais louças. Empilhar e carregar pratos e bandejas de forma a facilitar e encurtar caminhos é uma das habilidades desenvolvidas neste setor, além da aprendizagem do nome de pratos típicos, ingredientes e bebidas para harmonização oferecidas na casa.

\section{ESTRUTURAS DE APOIO}

Cada estagiário recebe a chave de um apartamento no dia da chegada e com ela um contrato em que estão as condições de uso e a obrigação de entrega, após o término do estágio, de devolver o ambiente e os móveis do mesmo modo como recebeu. O casarão onde estão os apartamentos é chamado de Alpseehaus (casa do lago), o qual era a antiga casa onde os cozinheiros, os jardineiros e os demais empregados da família real se estabeleciam. Os quartos, de aproximadamente $16 \mathrm{~m}^{2}$, são equipados com um balcão, uma cama de solteiro, um aquecedor, um bidê, um armário, uma mesa e uma cadeira, uma pia e um espelho, conforme Figuras 5 e 6 . Roupa de cama e banho podem ser retiradas na lavanderia do hotel.

Figura 5 e Figura 6: Quarto de intercambista
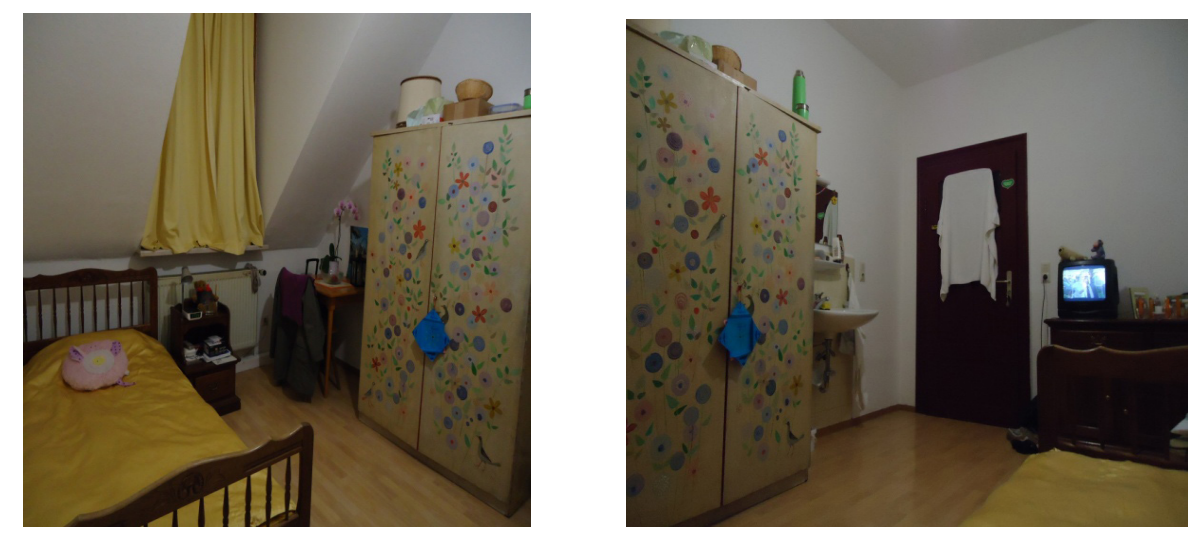

Fonte: Arquivo pessoal 
Todo intercambista tem direito a dois dias de folga por semana. Não há desigualdade na distribuição, pois eles atentam para a preferência dos funcionários de folgarem dois dias em sequência ou separadamente, podendo cair ou não em final de semana, depende da quantidade de reservas da semana e não há distinção entre funcionários fixos ou estagiários.

\section{DIAS LIVRES, SALÁRIO E CURSOS}

Nos dias de folga os intercambistas podem acessar os hotéis e os restaurantes por qualquer motivo de necessidade, podendo também se alimentar no restaurante dos funcionários como em qualquer dia. Nestas folgas os intercambistas estão livres para conhecer lugares, participar das visitas no vilarejo junto com os turistas, passear no lago, descansar, fazer compras ou visitar a cidade de Füssen, que é a mais próxima (Figura 7 e Figura 8).

Figura 7: Füssen

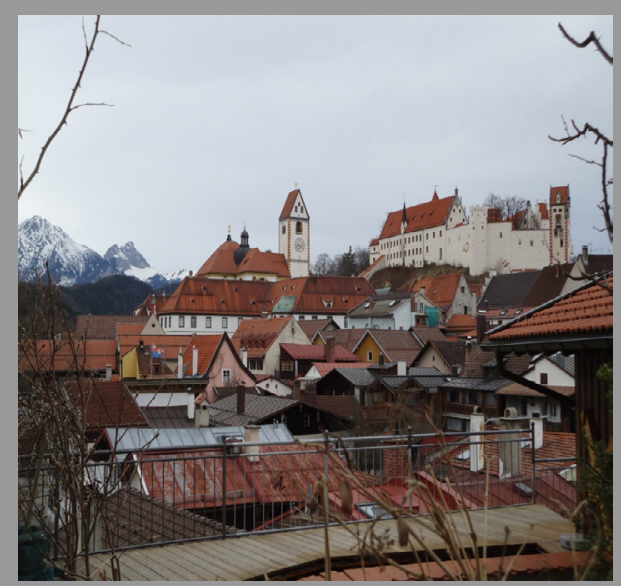

Figura 8: Lago Hopfensee

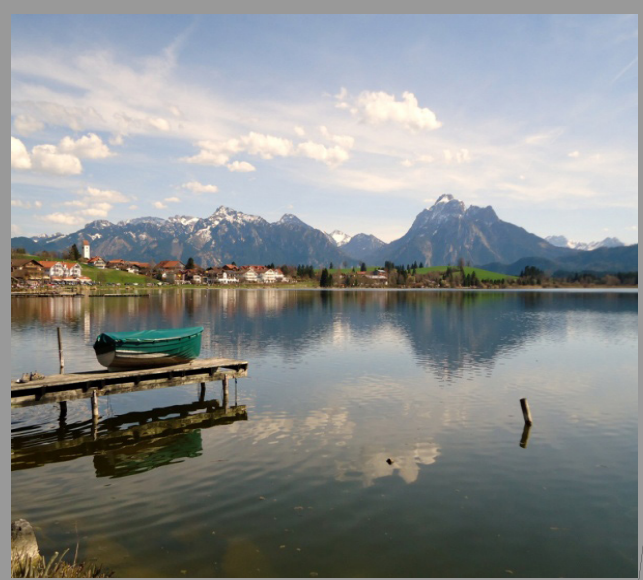

Fonte: Arquivo pessoal

Esses dias de folga servem ainda para conhecer os modos de vida locais, a cultura e também praticar o idioma indo a mercado, banco, lojas, igrejas, organizar um passeio para outra cidade distante, tomar sorvete, brincar na neve, tomar café com amigos ou ainda passar o dia na beira de um dos muitos lagos da região (Figura 8 - Hopfensee).

Os pagamentos são mensais e realizados via banco, em Füssen. A mesma precisa ser encerrada por cada participante ao final do contrato. Férias é um direito registrado de todo intercambista, que tem 30 dias de férias, assim como todos os outros trabalhadores da Alemanha.

O hotel oferece cursos para os funcionários com certa regularidade, desde primeiros socorros, etiqueta, montagem de mesa e técnicas para dobrar guardanapos, além de outros. Alguns deles, são para todos os empregados do complexo, já outros, então denominados de aula, são apenas para os estagiários que não cursaram Hotelaria. Destacam-se alguns cursos interessantes, como os Cursos de Café, Chá e Chocolate, ministrados e certificados pelas empresas que abastecem o hotel com estes itens. Já as aulas mais importantes, dadas por 
coordenadores do complexo, são as de história da família Wittellsbach e aulas de gastronomia, como as de corte para carnes e peixes, pratos flambados (Figura 9) e, ainda, aula sobre montagem e desmontagem de mesas.

Figura 9: Aula sobre Flambar

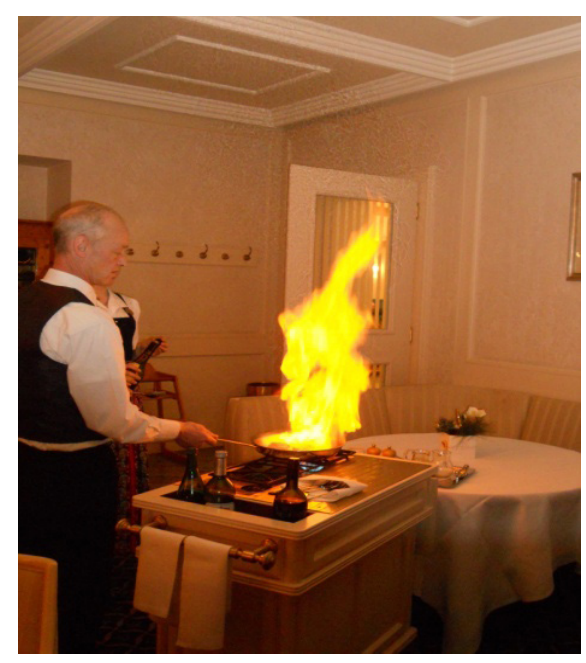

Fonte: Arquivo pessoal
Figura 10: Maybaum

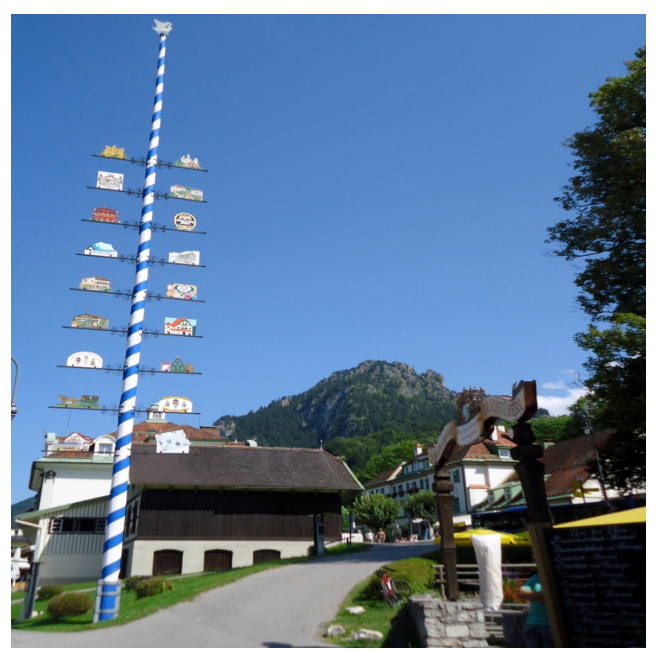

Como forma de interação com a cultura local, pode-se citar a participação em eventos realizados na comunidade, com possibilidades de conhecer mais sobre os modos de vida locais. O segundo maior evento realizado é no dia $1^{\circ}$ de maio, quando é comemorado o dia do trabalhador. Nessa data cada comunidade ou bairro celebra o Maybaum, que significa árvore de maio. O tronco pintado com as cores da bandeira da Baviera expõe as principais profissões dos moradores da região, conforme Figura 10.

Já o maior evento realizado nesta comunidade é o chamado Starkbieranstich. Anualmente, no mês de março, cada cervejaria da região produz uma cerveja com um teor maior de álcool e após uma votação, a melhor é produzida para consumo nesta festa.

Logo, foi possível observar as funções desempenhadas pelos intercambistas, as possibilidades de inter-relações com a cultura local, bem como as técnicas e os conhecimentos adquiridos por meio do intercâmbio.

\section{ANÁLISE}

Levando em conta o perfil dos participantes desta pesquisa, percebem-se, em sua maioria, integrantes do sexo feminino que representam $87 \%$ dos participantes e somente $13 \%$ das vagas foram ocupadas pelo sexo masculino. Essa minoria masculina pode ser considerada como uma exigência por parte da direção da Alemanha, pois o público feminino se mostra mais delicado e dedicado neste tipo de atividade, sendo que a maioria dos intercambistas brasileiros são mulheres. 
Uma grande parcela dos participantes possui 22 anos, o que representa $37 \%$ dos intercambistas. O índice demonstra que, quando realizaram o intercâmbio, esses mesmos participantes possuíam entre 18 e 20 anos, e naquele momento buscavam o caminho para transpor barreiras e limitações, deixando a insegurança, os preconceitos e as diferenças culturais darem espaço para surgir um novo indivíduo, conforme destacou Sebben (2007). Oportunidade esta ideal para combinar conhecimentos acadêmicos, com novas experiências pessoais e profissionais.

Esteves, Galdini e Magliocca (2011) alertam que, independentemente do momento que se escolha para se proporcionar esta experiência, o intercâmbio é uma ótima forma de complemento dos estudos. Considerando estes conceitos e o grau de escolaridade declarado nas pesquisas, é possível afirmar que mais da metade (62\%) possui Ensino Superior Incompleto, tendo optado por interromper a graduação para participar do programa em estudo.

Entre 2010, 2011 e 2012, a quantidade de participantes no intercâmbio foi idêntica. O primeiro grupo, em 2010/2011, representou 34\%, sendo que os anos de 2011/2012 e 2012/2013 representam 33\% cada, o que demonstra domínio e conhecimento profundo por parte dos responsáveis pelo intercâmbio na Alemanha, da necessidade e da possibilidade de hospitalidade destas pessoas no complexo turístico.

Quanto aos dados demográficos, pode-se perceber e confirmar que a proposta de intercâmbio foi bem divulgada, de forma que não se restringe a participantes somente do Rio Grande do Sul, da região do Vale do Rio dos Sinos, região do Vale das Hortênsias ou Vale do Caí (embora sejam estes os mais frequentes participantes, representando 25\%). Isso pode exemplificar como a globalização e a utilização de meios eletrônicos, como mídias sociais e internet de modo geral, têm potencial para divulgar e disseminar, cada vez mais, a disponibilidade deste tipo de turismo. Braga (2007) destaca que, com o aumento da necessidade de mão de obra qualificada, não somente os jovens estão interagindo na busca destas alternativas no exterior, mas também as empresas perceberam isso, versatilidade, qualificação e maleabilidade.

Quanto às profissões atuais dos pesquisados, apenas 25\% atuam na área do Turismo. Indo ao encontro com o que Panosso Neto e Ansarah (2009) explanam, é conveniente ao contexto pós-moderno viagens que visem a um aprendizado mais profundo por meio da diversidade de experiências no campo profissional e multicultural. A necessidade de aceitar inscritos que atuam em diversas áreas é em função dos poucos interessados que já trabalham no Turismo ou que tenham experiência na gastronomia e na hotelaria e, ainda, ter disponibilidade ou interesse em práticas mais aprofundadas.

As opções, segundo o grau de importância para cada um dos pesquisados, apresentaram variações interessantes. Nas respostas, a iniciativa obteve o segundo menor grau de importância, o que significa que pouco foi proporcionado ou aprendido sobre este fator, de modo que isto não veio alterar o desempenho dos participantes em suas atividades profissionais atuais. Com um roteiro de atividades preestabelecido que deve ser cumprido, tomar a iniciativa depende também do espaço conquistado e desenvolvido junto de cada setor e colegas de trabalho. Um setor, inicialmente não aberto, como local para atividades do intercâmbio era o departamento de reservas, em que somente os interessados que tomaram a iniciativa de solicitar esta possibilidade obtiveram sucesso e espaço para mais 
aprendizados. Sebben (2001) declara que, cada vez mais, as empresas querem em seus quadros funcionais pessoas de perfil arrojado, criativas e com iniciativa.

Com grau de importância ainda mais baixo do que o fator iniciativa está a criatividade, que obteve de $44 \%$ dos participantes o menor grau de relevância. Da mesma forma, a criatividade é restritiva e quando alguém propõe algo novo, passa por vários obstáculos antes de ser aprovado e aceito. Criativo pode ser positivo, mas em locais cobertos de regras e normas, às vezes, é preferível manter o padrão como garantia.

Quando questionados sobre a disciplina, observa-se que este item dividiu os participantes e os graus de importância dados a ela, sendo considerada por $31 \%$ como fator de muita importância, outros $31 \%$ declararam este fator como sendo o menos importante e, ainda, 38\% consideraram mediana a sua relevância.

Apesar de as quantidades percentuais serem similares e, mesmo assim distintas, a disciplina é um fator bastante pessoal, que foi exigido durante o ano de intercâmbio. Mas mesmo quando perceptível o desinteresse da pessoa por determinada tarefa, cabe principalmente ao participante declarar este fator como importante e determinante, ou não, para sua vida pessoal e carreira profissional. Este é um fator que possui papel importantíssimo na construção da carreira profissional, conforme destacam Esteves, Galdini e Magliocca (2011).

Outra questão foi em relação ao fator comprometimento, que surpreendeu de forma positiva pelo grau quase máximo de importância obtido por mais da metade dos participantes. Eles confirmaram que atividades em que o seu comprometimento foi trabalhado durante a experiência de intercâmbio ajudaram com o desempenho da atividade em que atuam atualmente. O comprometimento maior estava na decisão de aceitar as propostas do intercâmbio em hotelaria e gastronomia e se comprometer, dessa forma, com as condições e as atividades propostas pelo mesmo. Pessoas que enxergam nessas oportunidades amadurecimento e comprometimento têm potencial real de destaque no mercado de trabalho, segundo Esteves, Galdini e Magliocca (2011).

Líder de importância nessa pesquisa, a qualificação profissional, que segundo Braga (2007) é algo que deve ser trabalhado, pois a necessidade de mão de obra qualificada tem aumentado, foi o fator apontado como tendo sido o mais desenvolvido durante o período de intercâmbio, considerando os atuais campos de atuação. Sendo oferecido e promovido como uma oportunidade para qualificação de pessoas, o intercâmbio não deixa de desenvolver isto em nenhum momento durante o ano de prática, tomando como parâmetro os cursos, as palestras e as práticas diárias desenvolvidas em todas as áreas.

Nesse contexto, lembra-se de que a questão central do problema dessa pesquisa foi identificar quais as contribuições e os benefícios da realização do intercâmbio em Hotelaria e Gastronomia na Alemanha. Assim, considerando algumas categorias preestabelecidas, abordadas com frequência na literatura, observou-se que 63\% estão muito satisfeitos com o enriquecimento pessoal proporcionado nessa experiência na Alemanha. Este dado confirma o que Mac-Dowell (1998) descreve sobre as atividades que enriquecem o indivíduo de conhecimentos e o ajudam a apreciar e compreender melhor o mundo e sua própria cultura. A mesma autora afirma que as pessoas estão procurando, além das fronteiras, diversas formas de aprendizados, a fim de ampliar seus conhecimentos, o que 
complementa a questão feita sobre a satisfação dos participantes do intercâmbio quanto à ampliação do conhecimento, em que $88 \%$ responderam estar muito satisfeitos.

Conforme salientado por Tavares (2008), os resultados atestam que a busca de conhecimento na atualidade tem sido pelo aprofundamento de uma cultura, de uma língua ou da aérea de atuação. As técnicas aprendidas em todos os setores, somado aos cursos e às aulas e ainda à interação cultural, foram formas propostas disponibilizadas para trazer teórica ou praticamente novos conhecimentos durante o decorrer do ano de intercâmbio.

Segundo Mac-Dowell (1998), a melhor maneira para que haja a troca de experiências e vivências culturais é quando se vive em outro país por um período de tempo e, com isto, se aprende a conhecer um pouco mais sobre um povo, encontram-se pessoas diversas e conversa-se com elas, conforme os $75 \%$ de muito satisfeitos destacado na questão do intercâmbio em estudo.

Tendo ou não experiências internacionais anteriores, é próprio do homem tentar conhecer diferentes culturas, compreender o cotidiano de vida de outras sociedades, visitar destinos para compreender a história e cultura locais (MENEZES, 2004). A troca de experiências ocorre diariamente, rodeada de curiosidade, quando se é convidado a falar sobre o cotidiano no Brasil, quando se comparam métodos e práticas/posturas de trabalho, quando se detalham aspectos culturais e quando permitem viver a cultura local.

Ligado a isso, conhecer pessoas e países distintos é quase uma consequência de romper as fronteiras. Sebben (2007) concorda com esses pontos de vista, de modo que quando a pessoa decide participar de um intercâmbio, está de certa forma procurando se deparar com algo novo, conhecer pessoas diversas, com costumes diferentes dos que está acostumado, fazer novas amizades, viajar sem saber que, sobretudo, está indo ao encontro de si mesmo.

O intercâmbio em estudo abre espaço e coloca os participantes em contato com pessoas com as quais têm de aprender o que é o melhor, o pior, o conveniente, o típico, o clássico, o habitual, o importante, além de proporcionar condições de tempo para explorar o velho mundo durante o período de férias.

A questão que aborda a contribuição do intercâmbio para o amadurecimento, autoestima e autoconhecimento foi respondida com $88 \%$ dos participantes estando muito satisfeitos, contribuições que também são destacadas por Tavares (2008) como sendo alguns dos principais benefícios que uma pessoa obtém ao realizar um intercâmbio, assim como a autonomia e a liberdade que são desenvolvidas.

Esta afirmação também cabe para os aspectos referentes à liberdade e à autonomia que compunham outra alternativa da questão. Esses fatores deixaram 63\% dos participantes muito satisfeitos e apenas $37 \%$ apenas satisfeitos. Muito deste percentual declarado como apenas satisfeito está ligado ao cumprimento de normas e regras rígidas dentro do local de trabalho e também do próprio país, como é o caso da Alemanha.

Inegável e tão inevitável quanto se relacionar com outras pessoas e conhecer novos lugares está a prática do idioma. Exigência para muitas profissões atualmente, o intercâmbio na Alemanha é a oportunidade para pessoas perseverantes em aprender a língua, porém é claro que o convívio com outros brasileiros pode atrapalhar nos avanços dessa prática. 
Mac-Dowell (1998) complementa dizendo que é extremamente importante aprender um idioma e, para complementar, Esteves, Galdani e Magliocca (2011) concordam que todos os intercâmbios são ótimas maneiras de adquirir fluência no idioma local.

Como complemento à questão central, a primeira questão deste estudo, procurou-se identificar, apontando algumas atividades, ações e comportamentos proporcionados durante o intercâmbio na Alemanha, de que forma e com que grau de satisfação os participantes percebiam e estavam quanto ao desenvolvimento profissional.

O primeiro item da segunda questão abordava o desenvolvimento de habilidades profissionais e, conforme os resultados, deixou os intercambistas satisfeitos. Habilidades que, em razão de aprimorar os conhecimentos e agregar valor à atividade profissional, vai ao encontro do que foi defendido por Tamião (2010), quando afirmou que estas atividades têm o poder de diferenciação e enriquecimento do currículo, o que pode acabar contribuindo para o ingresso ou qualificação no mercado de trabalho. Muito além do aprender ou aprimorar um idioma o intercâmbio é, para Teles (2004), um laboratório onde se pode testar e desenvolver habilidades profissionais e a capacidade de enfrentar problemas por conta própria em um ambiente desconhecido.

A capacitação oferecida por meio de cursos, palestras e também atividades de integração de funcionários deixou os intercambistas parcialmente satisfeitos, na expectativa de um maior número de encontros e opções extracurriculares. Mesmo sabendo da dificuldade em reunir as equipes de trabalho com tanta frequência, a autora deste trabalho também concorda que, em épocas de baixo movimento, o tempo ocioso que existe poderia ser utilizado para momentos de capacitação.

As formas de capacitação, sejam elas por meio de cursos, seminários, palestras ou por meio da integração com as pessoas, são buscadas para reforçar habilidades ou conhecimentos necessários à atividade profissional, segundo Trigo (1998).

Somado a estes aspectos, a inserção na cultura local depende, neste caso, um pouco das atividades propostas e reflete a flexibilidade e a adaptabilidade que Esteves, Galdini e Magliocca (2011) indicam como evidências da atividade de intercâmbio, em que estes pontos são necessários para se adequar ao novo meio em que se está ou se quer ser inserido. Ainda quanto a questões que envolvem o comportamento, o relacionamento profissional, o respeito e a hierarquia, o intercâmbio ensina a respeitar colegas de trabalho e, primeiramente, clientes e turistas. O próprio idioma alemão impõe na gramática regras de linguagem que são utilizadas para discriminar hierarquicamente pessoas para com as quais se deve manter um relacionamento de maior respeito.

Sebben (2007) expõe que, ao aprender a aceitar e conviver com as diferenças, se sensibilizando, esquecendo os preconceitos e se declarando mais necessários uns dos outros, se está deixando nascer uma nova realidade, na qual pode tornar-se mais tolerante à diversidade em geral, independentemente de cor, raça, religião ou nacionalidade. Essa visão com certeza é desenvolvida quando se atende a todos os clientes da mesma forma e não se atenta para o quanto podem pagar ou com que pressa vão viver este conto de fadas, coerente com o conceito de turismo de intercâmbio comentado por Ferreira (2009), em que afirma que é durante este período de experiências que se percebe uma maior predisposição para aprender novos conceitos e teorias diversas. 
Neste intercâmbio as técnicas profissionais e o padrão de qualidade são pontos extras que agregam ainda mais valor tanto ao produto quanto à qualificação profissional, pois estas práticas profissionais são visíveis, principalmente em técnicas culinárias, técnicas de arrumação das mesas, técnicas de atendimento e a qualidade está no padrão exigido na arrumação dos quartos, nas vestimentas e em toda prestação de serviços a hóspedes e clientes. Para Trigo (2000), esta é uma área cada vez mais explorada, que amplia as possibilidades de turismo ligadas ao aperfeiçoamento e à atualização profissional.

É durante este período de experiências que se percebe a predisposição para aprender novos conceitos, práticas e teorias diversas, de variadas áreas do conhecimento, que são transmitidas por meio da observação e da vivência em destinos turísticos no mundo todo. Essa abordagem, que se pode definir como desenvolvimento intelectual, profissional e moral, é coerente e se encaixa no conceito de turismo de intercâmbio (FERREIRA, 2009).

Desse modo, por meio da realização dessa pesquisa, foi possível observar que o intercâmbio é em geral realizado por pessoas interessadas em agregar e aprofundar conhecimentos por meio de uma experiência de vivência em um país estrangeiro, pois se caracteriza por ser uma viagem de enriquecimento pessoal e profissional, com grande poder educativo, além de agente de inter-relações com pessoas e culturas diversas. Assim, para compreender as contribuições da realização do intercâmbio em estudo, realizou-se uma pesquisa por meio de aplicação de questionário com as pessoas que já haviam participado do intercâmbio em estudo, na Alemanha, nas edições de 2010, 2011 e 2012.

Observou-se ainda que o desempenho das funções nos quatro setores oportuniza uma ampla gama de conhecimento, interação e domínio de técnicas importantes para cada função. Além disso, a questão dos padrões de qualidade impostos, disciplina, pontualidade e agilidade nos serviços prestados, qualifica o intercambista profissionalmente. A vivência e a experiência profissional no complexo turístico também preparam o profissional para atender a diferentes demandas e diferentes gostos e culturas, proporcionando maior segurança no desempenho das funções nos diferentes setores do hotel.

Conforme citado por Sebben (2007), viajar e ter contato com outras pessoas e culturas em outros destinos implicam conviver com modos diferentes de vida que ensinam a respeitar os valores e as crenças, mostrando como administrar conflitos por meio da preservação das identidades, do patrimônio e do acolhimento.

É característico dos intercâmbios proporcionar o desenvolvimento da consciência social e moral do ser humano e contribuir de diversas formas para o crescimento pessoal e profissional, pois conforme Teles (2004), o intercâmbio é como um laboratório para testar e desenvolver habilidades de uso profissional e desenvolver a capacidade de enfrentar problemas por conta própria em um ambiente desconhecido e estranho. Longe de casa e da família, ele assume o protagonismo da suas decisões e ações.

Desse modo, o intercambista aprende a valorizar a sua família, amigos, local de residência, patrimônio público e sua cultura. Além disso, lhe é oportunizado o aperfeiçoamento de uma língua estrangeira, por meio da prática diária desse idioma, novas culturas e saberes e o desenvolvimento e aprimoramento de habilidades. 
Vale ressaltar os benefícios e as contribuições da realização do intercâmbio, pois os participantes desta pesquisa salientaram sobre a satisfação em relação aos aspectos que envolvem o desenvolvimento profissional. Para avaliar de modo geral os resultados obtidos nas questões que se considerou entre os benefícios e as contribuições da realização deste intercâmbio em Hotelaria e Gastronomia, bem como os fatores de desenvolvimento pessoal, deve-se levar em consideração que a grande diferença não está em fazer ou não o intercâmbio, mas sim em somar conhecimento, amizades, em como cada pessoa se envolve, dedica-se e aproveita a oportunidade, pois se está mais qualificado, preparado e seguro.

\section{CONSIDERAÇÕES FINAIS}

Conforme foi possível observar, por meio do desenvolvimento desse estudo, o turismo é considerado um dos setores mais prósperos em nível mundial. Seu crescimento se deve por ser, em muitos países, a principal fonte de renda e de desenvolvimento, gerando benefícios à população local.

Nesse contexto, observaram-se a segmentação do mercado em expansão e a diversificação na oferta das propostas de realização da atividade turística. Assim, destacou-se nesse estudo o Turismo de Intercâmbio realizado na Alemanha como segmento relevante para a formação pessoal e profissional, pois proporciona ao intercambista várias possibilidades de aproveitamento que geram conhecimento pessoal e profissional.

Destacou-se também que os intercambistas são motivados por vislumbrarem as possibilidades de realização individual pela oportunidade de viver sozinho e por conta própria (longe da proteção familiar), da imersão em uma nova cultura, pois passam a conhecer os modos de vida e a praticar o idioma local, seus hábitos e costumes, além de desenvolver novas habilidades profissionais dentro de um padrão internacional que envolve disciplina, formalismo, respeito e qualidade na prestação de serviços, conferindo experiências diversas daquelas experimentadas no cotidiano brasileiro.

Percebeu-se, ainda, o quanto os programas de intercâmbios estão sendo reconhecidos como fatores de desenvolvimento pessoal e profissional, por meio da quantidade de parcerias que estão sendo estabelecidas entre universidades, empresas públicas e privadas, promovendo e incentivando essas relações de trocas de conhecimentos e seus reflexos técnicos e socioculturais.

Nesse contexto, a opção de estudar o Intercâmbio em Hotelaria e Gastronomia realizado na Alemanha se mostrou eficiente, pois por meio deste foi possível responder ao problema de pesquisa, que buscou investigar quais foram as principais contribuições da experiência para os participantes do intercâmbio e também atingir o objetivo geral, que buscou investigar as contribuições para os participantes da experiência do intercâmbio em Hotelaria e Gastronomia, promovido entre AFEBRAE e Schloss Hotel Lisl GmbH \& Co. KG., na medida em que os participantes conseguiram perceber as mesmas durante a realização do intercâmbio e identificá-las com maior ou menor ênfase e importância. Os objetivos específicos trouxeram a relação existente entre o turismo, o turismo de intercâmbio, a cultura e ainda o intercâmbio utilizado, como exemplo de forma que esta ligação facilitou na resolução do problema, que buscava conhecer quais seriam as contribuições para os intercambistas em participar deste intercâmbio. 
Por meio desse estudo, ainda foi possível caracterizar a região e o complexo turístico na Alemanha. A descrição do caso em estudo serviu para melhor compreensão do intercâmbio e como apoio prático para todas as informações vistas no primeiro capítulo. Também se destacou igualmente importante a aplicação dos questionários para a obtenção da opinião dos participantes das edições de 2010, 2011 e 2012, quando revelaram as contribuições perceptíveis desta experiência de intercâmbio na Alemanha. O questionário aplicado serviu como ferramenta de extrema utilidade, que forneceu respostas para avaliar os benefícios e as contribuições da realização do intercâmbio. A partir da análise dos dados, foi possível mensurar o grau de satisfação dos participantes com relação às questões de desenvolvimento profissional, benefícios e contribuições.

Entre os resultados obtidos, observou-se que a realização desse intercâmbio proporcionou ao indivíduo a chance de vivenciar culturas diferentes, acumular conhecimento, aprender ou aperfeiçoar um idioma, adaptar-se a outros costumes, ser flexível e alcançar um crescimento pessoal, somente experimentado diante de experiências proporcionadas durante esta imersão.

\section{REFERÊNCIAS BIBLIOGRÁFICAS}

AFEBRAE. Disponível em: <www.afebrae.com.br. Acesso em: 26 ago. 2013.

ANSARAH, Marilia Gomes Reis. Como aprender turismo, como ensinar. v. 2, São Paulo, SP: Senac, 2001. . (Org). Segmentação do Mercado Turístico: estudos, produtos e perspectivas. Barueri, SP: Manole, 2009.

BAHL, Miguel. Viagens e Roteiros Turísticos. Curitiba, PR: Protexto, 2004.

BARBOSA, Melgaço Ycarim. Histórias da Viagem e do Turismo. São Paulo, SP: Aleph, 2002.

BARRETTO, Margarita. Turismo e legado cultural: as possibilidades do planejamento. Campinas, SP: Ed.Papirus, 2000.

BENI, M.C. Globalização do turismo: megatendências do setor e a realidade brasileira. 3. ed. São Paulo: Aleph, 2011.

BRAGA, Débora Cordeiro. Agência de Viagens e Turismo. São Paulo: Elsevier, 2007.

BRASIL. Ministério do Turismo. Marcos Conceituais. Disponível em: <http://www.turismo.gov.br/export/ sites/default/turismo/o_ministerio/publicacoes/downloads_publicacoes/Marcos_Conceituais.pdf>. Acesso em: 26 ago. 2017.

. Ministério do Turismo. Turismo de estudos e intercâmbio: orientações básicas. Brasília: Ministério do Turismo, 2008. Disponível em: <http://www.turismo.gov.br>. Acesso em: 22 fev. 2017.

. Ministério do Turismo. Marcos Conceituais. 2011. Turismo de Estudo e Intercâmbio. Disponível em: <http://www.brasil.gov.br/infraestrutura/2011/01/desembarques-domesticos-e-internacionaisbatem-recorde-historico-em-2010>. Acesso em: 26 ago. 2017.

. Ministério do Turismo. Marcos Conceituais. 2012. Turismo de Estudo e Intercâmbio. Disponível em: <http://www.dadosefatos.turismo.gov.br/export/sit es/default/dadosefatos/estatisticas_indicadores/ downloads_estatisticas/estatisticas_indicadores_turismo_mundo_2012.pdf>. Acesso em: 28 mar. 2017.

CASTELLI, Geraldo. Turismo: Atividade Marcante. 4ae ed. Caxias do Sul: Educs, 2001.

CUCHE, Denye. Noção de cultura nas ciências sociais. 2ª ed. Bauru, SP: Edusc, 2002.

DENCKER, Ada de Freitas Maneti. Métodos e Técnicas de Pesquisa em Turismo. $6^{\underline{a}}$ ed. São Paulo, SP: Futura, 2002. 
DENZIN, Norman K.; LINCOLN, Yvonna S. O planejamento da pesquisa qualitativa: teorias e abordagens. 2a edição. Porto Alegre: ArtMed, 2006.

DIAS, Reinaldo; AGUIAR, Maria Rodrigues de. Fundamentos do Turismo: conceitos, normas e definições. Campinas, SP: Alínea, 2002.

DIAS, Reinaldo. Introdução ao turismo. 1ํㅡㄹ ed. São Paulo, SP: Atlas, 2005.

Turismo e patrimônio cultural. Recursos que acompanham o crescimento das cidades. São Paulo, SP: Saraiva, 2006.

ESTEVES, Sofia; MAGLIOCCA, Renata; GALDINI, Danilca. Carreira: Você está cuidando da sua? Rio de Janeiro, RJ: Elsevier, 2011.

FERREIRA, A., VICTER, P. Marketing do turismo: um estudo descritivo sobre a imagem do curso de idiomas. Programa de Pós Graduação em Administração. FUMEC, 2009.

FRIEDRICH, Andreas. Maximiliasweg: Bayrische Alpen - vom Bodensee zum Königssee. München, Bergverlag Rother GmbH, 2013.

FUNK, Gaby. Bildatlas Reise Fuhrerallgäu. Stuttgart: Dumont Reiseverlag, 2013.

GIL, Antonio Carlos. Como elaborar projetos de pesquisa. 4ª ed. São Paulo, SP: Atlas, 2009.

IGNARRA, Luiz Renato. Fundamentos do turismo. $2^{\text {a }}$ ed. São Paulo, SP: Pioneira Thomson Learning, 2003. JOB, Hubert; MAYER, Marius. Tourismus und regionalentwicklung in Bayern. Hannover, AL: ARL, 2013.

KNAPP, Gottfried. Neuschwanstein. 2ª ed. Stuttgart, AL: Axel Menges Edition, 1999.

LARAIA, Roque de B. Cultura: um conceito antropológico. Rio de Janeiro, RJ:Jorge Zahar, 2003.

LOPEZ, Andréia. Negociação e a inteligência cultural: O caso da cultura Árabe. São Paulo, SP: Biblioteca 24horas, 2013.

MAC-DOWELL, Valquiria. Sem fronteiras. Guia prático para estudar no exterior do $1 \stackrel{0}{\text { g }}$ grau à pós-graduação. Rio de Janeiro, RJ: Campus, 1998.

MADIA, F. A. As mais importantes tendências do marketing para os próximos anos. São Paulo: Makron Books do Brasil, 2007.

MENEZES, José N. C. História \& Turismo Cultural. Belo Horizonte: Autêntica, 2004.

MOROSINI, Marília Costa. Estado do conhecimento sobre internacionalização da educação superior: conceitos e práticas. 2006.

MOTA, Keila Cristina Nicolau, Turismo de Intercâmbio in PANOSSO NETTO, Alexandre; ANSARAH, Marilia Gomes dos Reis. Segmentação do mercado turístico: Estudos, produtos e perspectivas. São Paulo: Manole, 2009.

NOVELINO, Camila Guedes. Turismo de Intercâmbio: turista ou morador uma análise sobre a vivência do intercambista. Disponível em:<http://www.ufjf.br/bach/files/2016/10/CAMILA-GUEDESNOVELINO.pdf Acessado em: 16/03/2019.

OMT. Turismo Internacional: Uma perspectiva Global. 2ª ed. Porto Alegre: Bookman, 2003.

PANOSSO NETTO, Alexandre e ANSARAH, Marilia Gomes dos Reis. Segmentação do mercado turístico, produtos e perspectivas. Barueri: Manole, 2009.

PEREIRA, Paulo. Profissionais e empresas: os dois lados de uma mesma moeda no mercado de trabalho. São Paulo, SP: Nobel, 2005.

PRODANOV, Cleber Cristiano; FREITAS, Ernani Cesar. Metodologia do trabalho científico: Métodos e técnicas da pesquisa e do trabalho acadêmico. 2ae ed. Novo Hamburgo: Feevale 2013.

RABAHY, W. A. Turismo e desenvolvimento: estudos econômicos e estatísticos no planejamento. São Paulo: Manole, 2003.

RODRIGUES, Adyr Balastreri. O turismo e desenvolvimento local. São Paulo: Hucitec, 2002.

SANTANA, Agustín. Antropologia do Turismo: analogias, encontros e relações. São Paulo, SP: Aleph, 2009.

SCHWANGAU. Die Königsschlösser. Disponível em: <http://schwangau.de/seine-schloesser-249.html>. Acesso em: 08 mar. 2014. 
Rev.Tur., Visão e Ação, v21, n2, p128-149, Mai./Ago. 2019 - Balneário Camboriú, Santa Catarina, Brasil

.Alle zimmer und Hotels. Disponível em <http://schwangau.de/hotel-zimmer.html?\&no_cache=1>. Acesso em: 08 mar. 2014.

SEBBEN, Andréa. Um estudo exploratório sobre o intercâmbio cultural com a contribuição da psicologia intercultural e da educação intercultural. Dissertação de mestrado. Centro de Filosofias e Ciências Humanas. Florianópolis: UFSC, 2001. . Intercâmbio Cultural - para entender e se apaixonar. Porto Alegre: Artes e Ofícios, 2007.

TAMIÃO, Talita Segato. Associação brasileira de pesquisa e pós-graduação em turismo (ANPTUR). São Paulo, SP: Universidade Anhembi Morumbi, UAM, 2010.

TAVARES, Adriana; et. al. Mercado de Intercâmbio. In: BRAGA, Débora (Org). Agências de Viagens e Turismo. São Paulo, SP: Elsevier, 2008.

TELES, João Marcelo de Melo. Intercâmbio. Coisas que todo jovem precisa saber. São Paulo: Melhoramentos, 2004.

TOMAZZONI, Edegar Luis; OLIVEIRA, Caroline Cunha de. Turismo de Intercambio: perfis dos intercambistas, motivações e contribuições da experiência internacional. Disponível em: https:// siaiap32.univali.br/seer/index.php/rtva/article/view/5116 Acessado em: 15/03/2019.

TRIGO, Luiz Gonzaga Godoi. A Sociedade pós-industrial e o profissional em turismo. Campinas, SP: Papirus, 1998.

. Turismo como aprender, como ensinar. 3ª ed. São Paulo, SP: Senac, 2000.

VASCONCELOS, Juliana Alves. Turismo de Estudos e Intercâmbio: a experiência dos intercambistas do curso de turismo da Universidade Federal Fluminense. Disponível em: https://app.uff.br/riuff/ bitstream/1/1036/1/317\%20-\%20Juliana\%20Vasconcellos.pdf Acessado em: 15/03/2019.

YIN, Robert K. Estudo de Caso: Planejamento e Métodos. Trad. Daniel Grassi. 3ª̣- ed. Porto Alegre: Bookman, 2006.

\section{CONTRIBUIÇÃO DE CADA AUTOR NA ELABORAÇÃO DO ARTIGO:}

ANDRÉIA CAROLINE SCHNEIDER: Referencial teórico, caracterização do objeto de pesquisa, metodologia, pesquisa de campo - tabulação e análise dos dados coletados.

MARY SANDRA GUERRA ASHTON: Referencial teórico, revisão da caracterização, metodologia e análise dos dados coletados. Revisão e ajustes no texto. 